\title{
A prática do(a) assistente social a partir da percepção do usuário do Centro Especializado em Reabilitação III Anita Garibaldi
}

The practice of the social worker from the user's perception of the Specialized Center in Rehabilitation III Anita Garibaldi

\author{
Roberto Correia Alves* \\ Hilderline Câmara de Oliveira** \\ Adna Rejane de Freitas Rego*** \\ João Batista Figueredo de Oliveira****
}

\section{Resumo:}

O artigo ora apresentado é resultado de uma pesquisa realizada no Centro Especializado em Reabilitação III (CER) Anita Garibaldi, vinculado ao Instituto Santos Dumont no Rio Grande do Norte, que teve como objetivo analisar a atuação do Serviço Social a partir da percepção do usuário; compreender a relação serviço social e pessoa com deficiência na perspectiva de garantia de direitos; conhecer como o profissional do serviço social atua frente aos desafios; discutir sobre as demandas do serviço social e sua dinâmica no CER III. A metodologia da pesquisa envolveu desde o levantamento bibliográfico até o trabalho de campo, utilizando-se de pesquisa exploratória com abordagem qualitativa, tendo como técnica de coleta de dados a observação com registro no diário de campo e a aplicação de entrevista semiestruturada ao público alvo do CER III. Os resultados apresentam uma estreita ligação entre a ajuda e o serviço social, entre uma profissão que se insere nos espaços na viabilização de direito e de um incompreendido objeto de trabalho, mas, que é atuante diante das demandas dos usuários e que se faz mobilizador junto a PcD. Considera-se que não há clareza no que se diz respeito a atuação do serviço social, mas que é importante para o CER e para o usuário.

Palavras-Chave: Serviço Social. Prática Profissional. Percepção. Pessoa com Deficiência. Saúde.

\section{Abstract:}

The article presented here is the result of a research carried out at the Anita Garibaldi Specialized Center for Rehabilitation III (CER), linked to the Santos Dumont Institute in Rio Grande do Norte, which aimed to analyze the performance of Social Work from the user's perception; understand the relationship between social service and people with disabilities from the perspective of guaranteeing rights; know how the social service professional works in the face of challenges; discuss the demands of social work and its dynamics at CER III. The research methodology involved from the bibliographic survey to the field work, using exploratory research with a qualitative approach, using observation technique recorded in the field diary and the application of semi-structured interviews to the target audience of the data collection technique. CER III. The results show a close link between help and social service, between a profession that is inserted in the spaces in making the right feasible and an incomprehensible object of work, but that is active in the face of users' demands and that is mobilized together the PwD. It is considered that there is no clarity regarding the performance of social services, but that it is important for the CER and for the user.

Keywords: Social Work. Professional Practice. Perception. Disabled Person. Health.

\footnotetext{
* Cursa Especialização em Saúde Pública e Serviço Social pela UNIFACEX, Natal/RN. Graduação em Serviço Social pela Universidade Federal de Pernambuco, Recife/PE.

** Assistente Social, Doutora em Ciências Sociais, Mestre em Serviço Social e Especialista em Antropologia Cultural também pela UFRN. Estágio de Doutoramento no Centro de Estudos Sociais (CES) na Universidade de Coimbra-Portugal.

*** Docente da UNINASSAU/RN. Doutora em Ciências Sociais pela Universidade Federal do Rio Grande do Norte.

**** Doutorando em Ciências Sociais - Universidade Federal do Rio Grande do Norte. Mestre em Ciências Sociais (UFRN). Graduação em Ciências Sociais pela Universidade Federal do Rio Grande do Norte.
} 


\section{Introdução}

O presente artigo é oriundo da experiência da residência em serviço social da residência multiprofissional no cuidado à saúde da pessoa com deficiência no período compreendido de 2018 a 2019, realizada no Centro Especializado em Reabilitação III (CER) Anita Garibaldi, vinculado ao Instituto Santos Dumont no Rio Grande do Norte.

O Serviço Social como profissão inserida nos CER's busca a maneira mais adequada de articulação da rede de assistência à pessoa com deficiência, considerando que o índice de pessoas com deficiência tem aumentado significativamente nos últimos anos e, consequentemente as demandas referentes a ela também.

Nesse sentido, o objetivo geral do artigo é analisar a atuação do profissional do Serviço Social sob a percepção do usuário do Centro Especializado em Reabilitação III - Anita Garibaldi, bem como, conhecer como o profissional da área atua frente aos desafios no espaço e discutir sobre as demandas do serviço social e sua dinâmica.

Assim, será exposta uma breve discussão sobre os aspectos socioeconômicos dos usuários envolvidos na pesquisa. Em seguida, foram eleitas categorias de análises a partir das entrevistas dos usuários, como: o serviço social como ajuda; a chegada do usuário ao CER; identificação da demanda do usuário; a grande demanda do transporte público; o serviço social e a equipe multiprofissional; e a resolutividade das demandas que chegam ao serviço social, e por fim as considerações finais.

\section{O surgimento do serviço social e dos CER's no Brasil e a PcD na história}

O serviço social no Brasil é historicamente permeado pelo pensamento caritativo da Igreja Católica e ganha tecnificação pela exigência da burguesia ao Estado por uma regulação social. A profissão tem seu marco de surgimento no processo de expansão da industrialização na década de 1930. Onde a população do campo que vivia no modelo agroexportador migra para as capitais brasileiras para o trabalho nas indústrias. Com essa mudança os problemas vão surgindo na organização de vida das pessoas e da sociedade. Conforme Yasbek (2009. p. 06):

As particularidades desse processo no Brasil evidenciam que o Serviço Social se institucionaliza e legitima profissionalmente como um dos recursos mobilizados pelo 
Estado e pelo empresariado, com o suporte da Igreja Católica, na perspectiva do enfrentamento e regulação da Questão Social, a partir dos anos 30, quando a intensidade e extensão das suas manifestações no cotidiano da vida social adquirem expressão política. (YAZBEK, 2009, p. 06)

Diante disso, a igreja católica que desde a Idade Média vinha perdendo espaço na cena política e econômica adentra na causa com o intuito de catequese da população que vivia em péssimas condições pela aglomeração desordenada nas cidades. E para atuar na situação foi implementada a ação social da igreja (YAZBEK, 2009), não somente como catequese, mas como caridade e o como ajustamento de condução dos indivíduos que precisavam ser adestrados para o trabalho nas fábricas.

É evidente a relação entre a profissão e o ideário católico na origem do Serviço Social brasileiro, no contexto de expansão da industrialização capitalista. Essa relação gera na profissão uma atuação visando uma abordagem da "questão social" como problema moral e religioso e resultando numa intervenção que privilegia a formação da família e do indivíduo para atendimento de suas próprias necessidades materiais, morais e sociais. Entretanto, o processo de constituição da profissão foi se alterando conforme a demanda da sociedade e o Estado requisitado pela burguesia passa a "implementar políticas no campo social" (YAZBEK, 2009) de forma mais sistemáticas, compondo a cena de tratamento das expressões da questão social junto a Igreja Católica.

Embora, essa ideologia que marcou a origem do serviço social esteja distante dos tempos atuais, ainda se vê na intervenção da profissão um misto de tecnificação com caridade e ajuda. Assim, "o serviço social ainda mantém traços [...] como: a valorização de qualidades pessoais e morais, o apelo ético, religioso ou político e o discurso altruísta e desinteressado." (YAZBEK, 2009, p. 12)

É no fim do período ditatorial que o arcabouço teórico-metodológico da profissão passa a assumir a defesa da classe trabalhadora. E a partir de então, a definição do serviço social como categoria, assumindo de forma definitiva a defesa intransigente dos direitos humanos, insere-se na luta entre a classe operária e os detentores dos meios de produção.

Isso, nos remete aos princípios fundamentais do Código de Ética da profissão, nos incisos II e III, que ratificam:

II. Defesa intransigente dos direitos humanos e recusa do arbítrio e do autoritarismo; III. Ampliação e consolidação da cidadania, considerada tarefa primordial de toda 
sociedade, com vistas à garantia dos direitos civis sociais e políticos das classes trabalhadoras. (BRASÍLIA, CFESS/CRESS, 2012, p. 23)

Nesse sentido, lamamoto (2008) assegura que o Serviço Social é uma profissão inserida da divisão sociotécnica do trabalho que tem um caráter sócio-político, crítico e interventivo, produto dos avanços teóricos-metodológicos, ético-político e técnico-operativo, que vem acumulando durante sua trajetória no enfrentamento das diversas expressões da questão social ${ }^{1}$ que se aguça no cenário contemporâneo. A autora acrescenta ainda que:

um dos maiores desafios que o profissional de serviço social vive atualmente é para desenvolver sua capacidade de decifrar a realidade, construir propostas de trabalho criativas e capazes de preservar e efetivar direitos, acordando atenção para a configuração da profissão não assentar em ações simplesmente executivas, mas também propositivas. (IAMAMOTO, 2008, p.20)

Vale salientar que com a descentralização das políticas públicas, positivada na Constituição Federal/1988, surge a necessidade de profissionais de distintas áreas, inclusive os assistentes sociais, para exercerem novas formas de atuação, aspecto que requer novas habilidades e competências para intervir na realidade, ou seja, diretamente no planejamento, na formulação, na execução e no processo de monitoramento e avaliação das políticas sociais, exigindo do profissional um alto nível de conhecimento e comprometimento para atuar junto a programas e projetos sociais, com atribuições que muitas vezes Ihes são privativas.

Corroborando as palavras de Almeida e Alencar (2011, p. 63)

As políticas sociais se originam de um conjunto de respostas historicamente elaboradas pelo estado no enfretamento da questão social que, do ponto de vista econômico, expressam um conjunto de ações dirigidas para a manutenção, dentro de limites que não comprometa a própria lógica da acumulação crescente do capital, patamares mínimos de consumo da classe trabalhadora.

De fato, na cena contemporânea, são muitos os desafios que se apresentam no cotidiano do fazer profissional do/a assistente social, mas temos o respaldo do projeto éticopolítico, que nos proporciona um exercício profissional mais ligado a outros projetos societários, permitindo cada vez mais uma dimensão política ampliada da realidade, guinado

\footnotetext{
${ }^{1} \mathrm{~A}$ expressão "questão social", tem um histórico recente, começou a ser utilizada na terceira década do século XIX, surge para nomear o fenômeno do pauperismo. A pauperização da população trabalhadora é o resultado do capitalismo industrial e crescia da mesma maneira que aumentava a produção (NETTO, 2001, p.42)
} 
assim, os profissionais para um projeto de transformação da sociedade. Por isso, Netto (1999), ratifica que o projeto ético-político do serviço social:

[...] apresentam a autoimagem de uma profissão, elegem os valores que a legitimam socialmente, delimitam e priorizam os seus objetivos e funções, formulam os requisitos (teóricos, institucionais e práticos) para o seu exercício, prescrevem normas para o comportamento dos profissionais e estabelecem as balizas da sua relação relações com os usuários de seus serviços, com as outras profissões e com as organizações e instituições sociais, privada e pública [...] (NETTO, 1999, p. 95)

Nessa perspectiva, as atribuições profissionais exigem conhecimentos e técnicas no âmbito da instrumentalidade do fazer profissional do/a assistente social. Tais conhecimentos estão relacionados aos fundamentos éticos, teóricos e metodológicos do trabalho social, que por sua vez implica de forma profícua na qualidade dos serviços prestados aos usuários. São conhecimentos no âmbito da instrumentalidade, que conforme Guerra (2007, p.02) está relacionada a "propriedade e/ou capacidade que a profissão vai adquirindo na medida em que concretiza objetivos. Essa instrumentalidade possibilita que os profissionais objetivem sua intencionalidade em respostas profissionais".

Como profissão que surge no seio da sociedade capitalista, o Serviço Social, atua em diversos espaços sócio-ocupacionais e dentre as instituições empregadoras deste profissional estão as que atendem a PcD, portanto, conhecer o processo histórico dela é fundamental.

Na história da humanidade a pessoa com deficiência (PCD) tem um processo bastante difícil e para compreendê-lo é necessário ser apreendido como período pré-científico e científico (BARTALOTTI, 2010), observando as concepções nos períodos históricos, pois são elas que se traduzem na forma de vida desse segmento.

A deficiência nos períodos históricos pré-científicos sempre foi vista como invalidez e as pessoas acometidas por ela eram pesos para sociedade. Assim, ser PcD significava viver à margem da sociedade, e em alguns povos, essas pessoas eram retiradas do convívio com os demais e abandonadas. Bem como, eram demonizadas como se fossem enviadas pelo "mal" para trazer problemas para àquele povo (XAVIER, 2015).

Com o Renascimento e a evolução científica, a visão sobrenatural sobre a deficiência é afastada, e não é mais o religioso que explica essa condição e sim a ciência. Não é, mas no espiritual que se encontra a resposta para essas questões, mas sim no próprio corpo pelo conhecimento científico. A partir de então, se tem outra concepção da deficiência. Há uma 
verdadeira mudança no que se concebia no período anterior, porém, até então ela era vista como doença (BARTALOTTI, 2010).

Desde a antiguidade é difícil ser considerado diferente numa sociedade que preza por padrões socialmente pré-estabelecidos. A discriminação e o não acesso a serviços básicos essenciais sempre estiveram presentes nesse segmento, que de certa forma se reconfiguram e se estendem até os dias atuais revestidos pela justiça e pela igualdade social. Entendidas aqui, através dos aparatos jurídicos e espaços que foram construídos com luta para garantia de direito, como a Convenção internacional sobre os Direitos das Pessoas com Deficiência e seu Protocolo Facultativo, de 13 de dezembro $2006^{2}$, que é um dos principais instrumentos de vitória desse segmento, e o Brasil como signatário promulga em de 25 de agosto o Decreto no 6.949/2009 em seu ordenamento validando a convenção em seu território.

Essa Convenção impulsionou mecanismos jurídicos por todo o mundo. No Brasil, o Estatuto da Pessoa com Deficiência, a Política de Atenção à Saúde da Pessoa com Deficiência, o Plano Viver Sem Limites, entre outros, foram exemplo de ordenamentos que trouxeram mais garantias e espaço para a PcD. Estabelecendo, assim, um pensamento humanizado e acolhedor para esse segmento que vislumbram garantias nunca tidas antes. Então, é nessa conjuntura histórica que a PcD está inserida, porém a construção e implementação de leis e espaços com o intuito de proporcionar melhorias ao exercício de cidadania da PcD não é suficiente, porque as leis nem sempre são cumpridas de forma satisfatória e os espaços não oferecem serviços que abarquem todas as necessidades dessa população.

Em relação ao indicativo populacional, no Brasil o número desse segmento é bastante alarmante. Com base nos dados da UNESCO ${ }^{3}$ mais de um bilhão de pessoas em todo o mundo vive com alguma forma de deficiência, destas quase 93 milhões são crianças. No Brasil, são 45,6 milhões de pessoas, que representam quase $24 \%$ da população brasileira com algum tipo de deficiência, dados que ratificam o Censo do ano 2010 onde o índice de PcD era de 24\% da população do país (IBGE, 2010).

\footnotetext{
${ }^{2}$ A Convenção sobre os direitos das pessoas com deficiência foi promulgada pela Assembleia-Geral das Nações Unidas (ONU), no dia 13 de dezembro de 2006 em Nova York, e, assinada pelo Brasil no dia 30 de março de 2007. Disponível em <http://www.planalto.gov.br/ccivil_03/_ato2007-2010/2009/decreto/d6949.htm>.

3 Disponível em <http://www.unesco.org/new/pt/brasilia/education/inclusive-education/persons-withdisabilities/>
} 
Diante do crescimento dessa população o acesso à saúde universal, integral e equânime deve ser propósito para atender de forma qualificada esse segmento. Entretanto, a saúde tornou-se um direito de todos e dever do Estado a partir da Constituição Federal de 1988. E no ano de 1990, foi criada a Lei Orgânica da Saúde, através das Leis no 8.080/1990 e 8.142/1990, as quais tratam da organização da política de saúde.

Com os dados levantados da população de PcD em mãos e sabendo de uma política de saúde para todos é possível alinhar o pensamento no que diz respeito ao melhoramento do acesso a bens e serviços com o propósito de autonomia da PcD e a inclusão social e, nesse sentido, os Centros Especializados em Reabilitação (CER) são serviços de atendimento à saúde desse público e têm se tornado referência na política de saúde em todo o país.

Os CER's surgiram no Brasil na década de 1950 (PEREIRA e MACHADO, 2015) com a criação de um Centro de Demonstração de Técnicas de Reabilitação da Organização Mundial da Saúde em São Paulo, e seguiam o modelo hegemônico de saúde. Com as especificidades geradas dentro das profissões de saúde nos séculos XIX e XX de forma mais definida (APARECIDA DE SOUZA, MANCUSSI e FARO, 2011), os atendimentos ficaram mais direcionados às necessidades da $\mathrm{PcD}$.

A demanda crescente por atendimento às $P c D$ passa a exigir a intervenção de profissionais de diversas áreas, no sentido de fortalecer e garantir os direitos previstos em lei, bem como melhorar a qualidade dos serviços prestados a este segmento e dentre essas profissões se insere o/a assistente social.

No universo de atuação do serviço social nas demandas alocadas ao profissional ao articular serviços da rede de atendimento, está o Centro Especializado em Reabilitação (CER). As demandas que chegam ao serviço social do CER III - Anita Garibaldi são as mais diversificadas possíveis, desde as demandas mais simples até aquelas que demandam mais tempo para sua resolução, têm suas particularidades e necessitam ser analisadas.

\section{Contextualização do objeto de estudo e o locus}

Ressalta-se que essa pesquisa, aprovada no Comitê de Ética - UFRN ${ }^{4}$, tem caráter

\footnotetext{
${ }^{4}$ sob o no 13932619.3 .0000 .5537$.
} 
exploratório com abordagem qualitativa com base na teoria social crítica. Foi realizado levantamento bibliográfico a partir de autores, que debatem sobre o tema. As técnicas utilizadas para coleta de dados foram a observação com registro em diário de campo e a aplicação de entrevista semiestruturada.

A pesquisa teve como locus de investigação o Centro Especializado em Reabilitação III (deficiências física, intelectual e auditiva) que faz parte do Centro de Educação e Pesquisa em Saúde Anita Garibaldi (CEPS), e este, junto com o Instituto Internacional de Neurociências Edmond e Lily Safra compõe o Instituto de Ensino e Pesquisa Alberto Santos Dumont (ISD), criado em setembro de 2013 e qualificado como Organização Social/OS, em fevereiro de 2014, através de Decreto da Presidencial, conforme a Lei no 9.637/98 que regulamenta as organizações sociais que se destinam a ensino e pesquisa científica. ${ }^{5}$

A pesquisa científica é um dos objetivos da instituição, que alinha o que é pesquisado com a assistência à saúde dos usuários do serviço, fortalecendo a atuação profissional, ou seja, constituindo um forte laço entre pesquisa e atuação. Como foco também da instituição, a multi/interprofissionalidade está presente no CER, reunindo profissionais de diversas áreas, onde se faz presente a profissional de Serviço Social e os residentes através da Residência Multiprofissional no Cuidado à Saúde da Pessoa com Deficiência.

No CER são atendidas as seguintes condições de saúde e deficiências: lesão medular (adulto e infantil), microcefalia, autismo, epilepsia (adulto e infantil) prematuridade e parkinson, que fazem terapia, consultas e atendimentos nas especialidades: neurologia, urologia, psicologia, fisioterapia, terapia ocupacional, fonoaudiologia e serviços social.

A equipe de serviço social do CER é composta por uma profissional contratada pela unidade com carga horária de 20 horas semanais e 04 residentes da residência multiprofissional no cuidado à saúde da PcD que compre 60 horas semanais entre atividades práticas e teóricas. O espaço de atendimento é composto por uma sala com um espaço menor para atendimento individual. A rotina da equipe se reveza entre atendimentos individuais, atividades em grupos, reuniões e planejamentos.

O CER funciona como serviço de porta aberta e para acessar os usuários precisam ligar para a central de marcação (interna) para marcar triagem, após essa etapa se for elegível

\footnotetext{
${ }^{5}$ Disponível em: http://www.institutosantosdumont.org.br/sobre-isd/. Acesso em 10 de fevereiro de 2019
} 
para o serviço é encaminhado para o Serviço Social para realizar o acolhimento institucional, que são orientações sobre as regras do serviço. Em seguida, é agendada na recepção a avaliação global com equipe multiprofissional ou a avaliação médica em algumas ocasiões.

$\mathrm{Na}$ avaliação global será feita uma investigação mais detalhada e o paciente será encaminhado internamente para o profissional que sua necessidade demandar e também para os grupos multiprofissionais. No caso de epilepsia e do parkinson é um pouco diferente, após a triagem passa-se à avaliação médica para atendimento conforme as características da condição de saúde.

Para os casos inelegíveis para o CER, o profissional que faz a triagem fará encaminhamento para a rede de saúde para usuário ter sua demanda atendida. Nas situações em que o usuário ou sua família demandem por orientações mais específicas, o profissional que realiza a triagem encaminha para o serviço social.

As condições objetivas do público da pesquisa são peculiares a metade da população brasileira que vive com menos de um salário mínimo ${ }^{6}$. Compreende-se que diante dessa realidade que os níveis de escolaridade, econômico e o de acesso a bens e serviços são limitados. Entretanto, evidencia no sentido mais teórico dentro do arcabouço da profissão que é um público bastante representativo das expressões da questão social.

Como descreve lamamoto (2009, p. 31), "a 'questão social" é mais do que a pobreza e desigualdade, ela expressa a banalização do humano, resultante de indiferença frente à esfera das necessidades das maiorias e dos direitos a elas atinentes".

No processo de observação de campo, constatou-se que ainda é a mulher a principal cuidadora dos filhos. E não é diferente se tratando de $P c D$, porque historicamente são elas que fazem o trabalho doméstico. Assumem tarefas que possivelmente caberiam a mais de um indivíduo desempenhar, pois o cuidado a PcD requer muito do cuidador, tanto no tocante a realizar atividades propriamente dita como em questões emocionais.

Alguns atendimentos/serviços como terapias e consultas no CER muitas vezes são remarcados pela falta do usuário, isso talvez pelo baixo poder econômico dele que se traduz algumas dificuldades como: a alimentação - fora de casa quando o usuário precisa passar o

\footnotetext{
${ }^{6}$ A metade mais pobre da população, quase 104 milhões de brasileiros, vivia com apenas $\mathrm{R} \$ 413$ mensais, considerando todas as fontes de renda. Disponível em <https://noticias.r7.com/economia/metade-dosbrasileiros-vive-com-apenas-r-413-por-mes-mostra-ibge-16102019>
} 
dia no CER -; a falta de material de higiene, fraldas, sondas e outros, são fatores que impossibilitam a vinda ao serviço.

As secretarias de saúde dos municípios da região de saúde que está localizado o CER muitas vezes não disponibilizam o transporte sanitário, e quando sim não é de forma contínua e efetiva para as terapias, dificultando o atendimento contínuo do indivíduo no serviço, e ainda tem resistência em entender quem é $P c D$, apontando para aqueles que têm aparentemente visível seu quadro de deficiência.

Assim, as condições que vivem esses usuários são as expressões da "Questão Social", que se origina "no marco da sociabilidade imposta pelo capitalismo, na tensão entre o processo de produção de desigualdades sociais e o processo de resistências e rebeldias da classe trabalhadora" (BARISON; GONÇALVES, 2016, p. 45).

\section{O serviço social representado pela visão do usuário}

Nos depoimentos obtidos através das entrevistas sem especificar perguntas, no contexto mais geral da fala, a palavra "ajuda" se relaciona ao serviço social como principal representação/sentido da profissão, como segue:

\footnotetext{
“Então, assim o serviço social ajudou muito. Me ajuda muito e ajudou muitas pessoas. [...] Ajuda muito a gente porque é bem difícil a nossa vida. Bem complicada. Difícil não é! É bem complicada" (entrevistado 01).

"Assim, quando a gente precisa né, eles (assistentes sociais) tão ali pra ajudar" (entrevistado 02).

“[...] - Falem com as pessoas da assistência social que eles ajudam" (Entrevistado 01).
}

É evidenciado a presença repetitiva da palavra a ajuda (e variações) ao serviço social, mesmo alguns com maior certo conhecimento se refere a profissão como a ajuda essencial no momento da necessidade. A palavra ajuda (substantivo e variações do verbo) foi encontrada 38 vezes em um texto de 21 páginas, reforçando o entendimento de que há uma ligação entre o atuar da profissão e a caridade.

O serviço social no Brasil é historicamente permeado pelo pensamento caritativo da Igreja Católica e ganha tecnificação pela exigência da burguesia ao Estado por uma regulação social. A igreja católica que desde a Idade Média vinha perdendo espaço na cena política e 
econômica adentra na causa com o intuito de catequese da população que vivia em péssimas condições pela aglomeração desordenada nas cidades, pelo processo de industrialização com início na década de 1930. (YAZBEK, 2009)

Assim, para atuar nesta situação foi implementada a ação social da igreja, não somente como catequese, mas como caridade e como ajustamento de condução dos indivíduos que precisavam ser adestrados para o trabalho nas fábricas. Essa filosofia era operacionalizada pelas mulheres cristãs católicas daquela época, como assevera Yasbek:

É por demais conhecida a relação entre a profissão e o ideário católico na gênese do Serviço Social brasileiro, [...]. Relação que vai imprimir à profissão caráter de apostolado fundado em uma abordagem da "questão social" como problema moral e religioso [...] para solução dos problemas e atendimento de suas necessidades materiais, morais e sociais. (YAZBEK, 2009, p. 03)

É possível perceber pela fala dos entrevistados uma ideia de que o serviço social não é uma profissão inserida no espaço sociotécnico do trabalho, e sim uma ação sem sentido de trabalho, que visa a ajuda ao próximo com embasamento religioso caritativo. Na fala que segue pode-se ainda vincular a profissão a religiosidade na ação da caridade ao próximo que moralmente se encontra em situação de miserabilidade e precisa da ajuda dos religiosos.

\footnotetext{
"Olha ajudou, porque realmente esse era meu sonho de ser serviço social. Era meu sonho fazer essa faculdade, tanto que prestei vestibular e passei, mas as condições da época não me permitiram ir. Ai, eu fui pra administração, mas sempre voltada a ajudar o próximo. Eu tenho um trabalho voluntário na igreja que eu frequento e a gente está sempre pronto" (Entrevistado 03).
}

Observa-se que a questão da ajuda é determinante nas falas dos usuários e nessa última traz um teor religioso de ajuda ao próximo e fortalecendo essa percepção com o trabalho voluntário realizado em espaços religiosos. Ainda que, tais ações sejam algo louvável para a humanidade, entendendo-a como solidariedade, o serviço social não pode ser associado a essas ações, porque como profissão demandada pela sociedade e utilizando-se das políticas sociais como instrumento de trabalho, ela não é voluntariado nem muito menos ajuda ao próximo.

Não podemos esquecer que, como ressaltam Almeida e Alencar (2011): o reconhecimento do trabalho como atividade social é central para pensar a inserção do serviço social na divisão sociotécnica do trabalho como atividade especializada, que participa das 
estratégias de controle sobre as condições de vida e de trabalho da classe que vive do seu trabalho.

Observamos no depoimento seguinte o direito do benefício eventual toma essa característica de ajuda, muito determinante:

“[...] uma cesta básica, uma visita, é uma coisa que eu gosto e quando eu trabalhei em um hospital eu ajudava a assistente social com eventos, pra levar os pacientes, pra passeios. Então, é uma coisa que eu gosto" (Entrevistado 03).

A cesta básica presente na atuação da profissão desde suas origens, traz um caráter caritativo de ajuda àqueles que estão em necessidades de proventos alimentar. Mas, como já esclarecido, fazendo-se necessário reforça, a cesta básica ${ }^{7}$ é um benefício eventual de caráter temporário da proteção social básica. A intenção do benefício é imediata, atender aquela situação posta superficialmente, mas a atuação do serviço social busca entender o motivo daquela situação e atuar no sentido de sanar de forma mais efetiva.

Ainda se referindo ao trecho: “ajudar na realização de eventos e levar pacientes a passeios" enfatiza a ideia de inferiorização da profissão no espaço de saúde. Mesmo sabendo que o lazer compõe os determinantes sociais de saúde ${ }^{8}$ e é direito do cidadão, surge a pergunta: Porque o profissional de serviço social na maioria das vezes nos espaços de saúde é ele quem executa essas atividades? Sem se aprofundar na questão, talvez alguns profissionais da área não compreendam seu papel no espaço de trabalho ou de forma coercitiva, a instituição estabelece essa tarefa para o profissional.

Em suma, os elementos trazidos nas falas reforçam a ideia de profissão que é incompreendida no local de trabalho, e deixa claro que os usuários está sempre pensando a profissão como a ajuda ao próximo, não porque essa ajuda seja direito do indivíduo, mas porque este por questões subjetivas e singulares não ascendeu socialmente e necessita dessa ajuda.

\footnotetext{
${ }^{7}$ Tipificação Nacional dos serviços socioassistenciais. Disponível em $<$ https://www.mds.gov.br/webarquivos/publicacao/assistencia_social/Normativas/tipificacao.pdf> ${ }^{8}$ disponível em <https://pensesus.fiocruz.br/determinantes-sociais>
} 
É a partir desses princípios, definido por lamamoto como arranjo teóricodoutrinário ${ }^{9}$, que o serviço social dar seus primeiros passos no país, e perdurando essa marca inicial até os dias atuais, não como tal, mas com outras configurações. A exemplo disso é percebido que Centro de Referência da Assistência Social no bairro onde se localização é compreendido na maioria das vezes pelos populares como o espaço de concessão da cesta básica (caridade), quando na verdade se trata de um benefício eventual constituído como direito daquele que necessita.

Embora, essa ideologia que marcou a origem do serviço social esteja distante dos tempos atuais, ainda se vê na intervenção da profissão um misto de tecnificação com caridade e ajuda. Por este motivo, que a profissão precisa se aproximar cada vez mais do seu projeto ético-político, para que possa desenvolver ações, que contribuam para a emancipação do sujeito e assim ele se perceba como sujeito de direitos. Ademais, Almeida e Alencar (2011, p.60) mostram que: "as ações profissionais estão relacionadas ao desenvolvimento de programas, projetos e atividades voltadas para garantia de direitos [...]."

\section{A chegada do usuário ao CER}

Conforme já descrito aqui, para o usuário se tornar elegível pelo CER segue algumas etapas, desde triagem até a primeira consulta ou terapia, e recente houve mudança na admissão para o serviço funcionando todo contato do usuário por telefone ${ }^{10}$. Mas, conforme fala da usuária quando indagada de como chegou ao serviço, verifica-se outras formas de se articular para o acesso:

“[...] Conheci uma amiga a mãe de uma paciente. Paciente que já era daqui, fazia tratamento. Então, ela me indicou. Ele (filho) "tava" sem fazer tratamento. "Tava" quatro anos sem fazer tratamento e "tava" precisando pra passar por uma cirurgia e o médico dele atendia aqui. Aí, ela (amiga) como já tinha conhecimento foi conseguir pra mim aqui essa vaga pra ele (filho). Eu vim, aí o médico é Dro Ângelo, neuro fez a triagem, né, tudinho, foi atendido por ele [...] (Entrevistado 04).

\footnotetext{
${ }^{9}$ Caracteriza-se pela união entre o discurso humanista cristão com o suporte técnico-científico da teoria social positivista, traz a profissão o caminho do pensamento conservador (pela mediação das Ciências Sociais) (YASBEK. 2009)

${ }^{10} \mathrm{O}$ acesso ao CER atualmente funciona através da ligação do indivíduo para a central de marcação da unidade para marcar triagem, que é o primeiro contato com o serviço, para verificar se a demanda dele se enquadra nos protocolos de atendimentos do serviço.
} 
Com base nas falas, há uma solidariedade entre essas mães/cuidadores e alguns profissionais da rede de saúde que estão atentos às demandas dos usuários com uma visão mais integral do sujeito e fazem esse encaminhamento para a reabilitação no CER. Ainda também, funciona o "boca-a-boca" pelos parentes de usuários que já conhecem o serviço faz indicação para aqueles que não sabem da existência da unidade de saúde. Mas, em outras ocasiões funciona também pelo encaminhamento de outra unidade de saúde, como segue:

\footnotetext{
"Foi depois que eu descobrir que minha filha tinha epilepsia. Ai a gente foi encaminhada pra cá, para o neuropediatra [...] lá do postinho da minha rua." (entrevistado 01). "[...] Aí, no posto de saúde uma fisioterapeuta foi que encaminhou para o tratamento no Anita, daí eu fiquei sabendo da existência do Anita que eu não sabia. Aí, trouxe ele (esposo) pro Anita, marcamos e teve toda uma triagem, daí ele foi aceito para fazer o tratamento e foi isso" (Entrevistado 03).
}

Verifica-se, na fala de uma delas, que existe certa insatisfação no acesso aos serviços de saúde de reabilitação, e alega que no município que reside é muito difícil conseguir vaga: "Eu soube por uma amiga minha que faz tratamento do menino dela aqui também. Aí ela me indicou. Ela veio mais eu. Ai, eu consegui a vaga. Porque é difícil conseguir uma vaga onde a gente mora" (entrevistado 02).

Essa é uma realidade difícil não só na 7ạ região de saúde no Rio Grande do Norte, onde está localizado o CER, mas em todo território nacional, a restrição na política sociais que atinge diretamente a saúde tem reduzido os espaços de atendimento à saúde e os cidadãos ficam soltos pela rede de saúde sem ter atendimento qualificado para sua necessidade e na maioria das vezes buscam os serviços privados. Isso nos remete a fala de Almeida e Alencar (2011), compreender o significado e o alcance da relação entre as políticas públicas e as formas institucionais concretas, que assumem na esfera local, implica entender em que medida o esvaziamento da política da vida social é parte da hegemonia do sistema capitalista.

Sendo assim, essa realidade limita a realidade financeira dessas famílias quando pagam pelos serviços e produtos que deveriam acessar gratuitamente no Sistema Único de Saúde. Isso porque, de seu orçamento restrito e apertado incluem despesas com saúde que para o público em estudo é muito mais custoso devido as especialidades profissionais para suas respectivas demandas, conforme assevera parentes de usuários: 
“[...] E eu vinha pra cá pagando... pagando, vinha de carona, de moto”. (entrevistado 01).

“[...] Ela não tava recebendo sonda na minha cidade. O certo é pra ela receber 180 por mês. Eu não tava recebendo eu estava comprando. [...] e esse mês eu não recebi e só me dão 100, não sei porquê. Eu compro mais do que ganho na minha cidade. Esse mês eu mandei o motorista comprar em natal, porque eu não recebi. Porque o rapaz não fez o pedido aí eu compro mais do que ganho. E fralda nunca ganhei" (Entrevistado 07).

Portanto, para o serviço social a garantia do acesso gratuito, universal e qualificado no SUS se torna solicitação fundamental para a orientação das famílias. Assim, ao chegar ao CER o trabalho do profissional de serviço social é de acolher aquela família orientar sobre regras de funcionamento do serviço, identificar o processo pelo qual passa o usuário e seu grupo familiar, atentando para as demandas presentes naquele momento para as possíveis articulações com a rede.

A prática de acolhimento pelo serviço social a todos os usuários que chegam ao setor é recente e para aqueles que antes, desta forma de acolher já estavam no serviço lançou-se mão da indagação na entrevista de como ele (usuário) chegou até o serviço social, e percebese que a maioria não sabe da existência da profissão no espaço ou não entendem o fazer profissional, consoante segue: “Não. Não. Só o (serviço social) daqui mesmo, (o primeiro contato) foi aqui no Anita Garibaldi" (entrevistado 06). Isso, não significa, que o profissional não disponha de relativa autonomia, mas sim, que o processo histórico da profissão ainda está mesmo na contemporaneidade, enraizado pela prática do assistencialismo e a invisibilidade, em alguns casos, de suas atribuições/competências do seu fazer profissional.

Ademais, na fala de outra entrevistada mostra que até conhece o serviço social e alega que na empresa que trabalhava tinha tal profissional, mas nunca recorreu a intervenção dele: “Bom, não, porque em são Paulo a gente tinha convênio e usava o convênio e na empresa que eu trabalhava tinha um serviço social da empresa, mas só aqui mesmo no Anita que eu recorri ao serviço social" (entrevistado 03).

O desconhecimento da profissão e do trabalho da profissão é perceptível quando se sabe que a maioria dos cidadãos, principalmente a população trabalhadora usuária desse serviço público que teve seu direito violado ou está sendo negligenciado. Dessa forma, é possível afirmar o porquê o contexto sociopolítico atual é de restrição de direitos e as políticas 
e programas sociais continuam sem atender o princípio da universalidade amparado pela Carta Magna de 1988.

\section{A prática do serviço social no CER}

Os instrumentais utilizados pelo serviço social no espaço são diversos e fundamentais para a concretização e reconhecimento da profissão. São eles que mostram ao CER e a sociedade a imagem da profissão e, ainda é através deles que os assistentes sociais podem efetivar seus objetivos e suas finalidades profissionais (GUERRA, 2000). Quando questionados os usuários por esses instrumentos e a atuação do serviço social temos as seguintes falas:

\footnotetext{
“Tudo faz parte de um conjunto profissional e dá sustentação para o paciente que tá com parkinson. É muito e maravilhoso isso aí. É muito acolhedor" (Entrevistado 06).

“[...] Eu vejo o serviço social até mesmo quando eu estou aí esperando o término do tratamento do meu marido, então eu vejo o serviço social conversando, dando cartinha, passando as informações, atendendo as pessoas com muito carinho" (Entrevistado 03).
}

Em alguns atendimentos utiliza-se de um questionário socioeconômico com perguntas direcionadas para a renda, escolaridade, habitação, meio de transportes e apoio da família, entre outros. Isso com o intuito de verificar a adesão ao serviço e intervir conforme necessidade.

\footnotetext{
“[...] Ela (assistente social) perguntou como era o transporte. eu falei. Ela foi me deu uma requisição pra eu entregar lá (secretaria de saúde), que eu tinha que vir terça, quinta e sexta. Pra eu entregar lá já a eles, pra ficar já normalizado" (entrevistado 02).

"A gente não tem formação de nada e a gente procura assistente social e nos orienta" (Entrevistado 07).
}

As rodas de conversas e as palestras que ocorrem nos grupos multiprofissionais são também relevantes para a atuação do serviço social no espaço. Conforme fala que segue, deixa claro que a atividade em grupo foi muito importante para compreensão do transporte gratuito para a PcD: "Teve aquele dia do encontro de grupo que a gente fez uma dinâmica que foi sobre os transportes. [...]" (entrevistado 01).

Como na unidade não há todas as especialidades das áreas de saúde que demandam a PcD recorre-se a outras instituições para realizar consultas e terapias pontuais para os usuários do CER. Desde 2012 a Portaria de no 793, constituído a rede de atenção à PcD e é 
através dela que se pode efetivar alguns atendimentos de especialidades que não tem no CER. O instrumental utilizado neste caso é a ficha inter-cer, instrumento utilizado pelo serviço social para a articulação com outros serviços para atendimento do usuário originário do CER Anita Garibaldi.

O livro de registro é fundamental para o serviço social, pois é nele que é feita todas as anotações/observações sobre os atendimentos mais complexos. Por exemplo, se tratando de uma demanda de negligência o serviço social vai precisar anotar todos os fatos e atendimentos para produzir um relatório para encaminhar para espaços como conselho tutelar, atenção básica, escola, etc.

Os documentos de encaminhamentos são de usos contínuos dentro da atuação da profissão, uma vez que o usuário procura o serviço com alguma demanda e não tem conhecimento de qual instituição procurar para resolver sua dificuldade, prepara-se um encaminhamento e junto com ele às orientações para o usuário levar a instituição que poderá atender. Como segue:

“O serviço social fez uma carta para eu levar lá no setor de transporte (secretaria de
saúde), pra pessoa responsável do setor de transporte e aí nós agendamos o momento, [...]" (entrevistado 03).

“Ela me deu uma papelada já pronta que é para eu não tá... se não fosse devida essa papelada eu "tava" correndo de um lado pro outro. Preparou pra mim as papeladas. Me deu já preenchida. Me ajudou na dúvida que eu não sabia, [...] (Entrevistado 08).

Ainda como rotina da prática da profissão no CER as ligações telefônicas são fundamentais, porque nem sempre o documento enviado a instituição vai ser analisado de imediato, então no intuito de reforçar o documento físico a ligação telefônica é o caminho utilizado como intermediação pelo serviço social entre o usuário e a instituição demandada, conforme usuária:

"[...] Começou vim (transporte do município) depois parou. Eu parei de vim uns dias por causa do carro. Aí foi tempo que foi você (pesquisador) dessa última vez que você me procurou, né, que tinha como se resolver, né. Conversei com você e, você me falou. Ligou, né, pra pessoa lá do carro, do transporte e até aqui está dando tudo certo e eu só tenho que agradecer" (Entrevistado 04).

As anotações no livro de registro, as intervenções junto ao usuário e a observação no espaço são ferramentas utilizadas para produzir relatórios sociais. Estes na atuação do serviço social no espaço são fundamentais, visto que os atendimentos no espaço são na maioria das 
vezes contínuos pela condição de saúde dos usuários havendo a necessidade de acompanhamento continuado.

Dessa forma, a utilização dos instrumentais elencados são parte do acervo técnico operativo da atuação do serviço social no CER. São eles que dão instrumentação a profissão e é através deles que se pode perceber a parte mais concreta do fazer profissional do serviço social.

\section{A identificação da demanda do usuário}

Para entender como o usuário chega até o serviço social ou se ele foi procurado pelo profissional, ou encaminhado por outro profissional, lançou-se mão da indagação e resultou:

Quadro I - identificação da demanda

\begin{tabular}{|l|c|c|c|}
\hline & \multicolumn{3}{|c|}{ Identificada por: } \\
\cline { 2 - 5 } & serviço social & usuário & profissional interno \\
\hline entrevistado 01 & $\mathrm{X}$ & & \\
\hline entrevistado 02 & & & $\mathrm{X}$ \\
\hline entrevistado 03 & & $\mathrm{X}$ & \\
\hline entrevistado 04 & & & \\
\hline entrevistado 05 & $\mathrm{X}$ & & $\mathrm{X}$ \\
\hline entrevistado 06 & & $\mathrm{X}$ & \\
\hline entrevistado 07 & & $\mathrm{X}$ & \\
\hline entrevistado 08 & & $\mathrm{X}$ & \\
\hline
\end{tabular}

Fonte: retirado das entrevistas, 2020.

Os dados mostram que os usuários procuraram por conta própria o serviço social, 02 foram encaminhados por profissionais da instituição e 02 identificados pelos profissionais de serviço social. Dessa forma, mesmo existindo dificuldade de compreensão do fazer profissional, mas entendendo o serviço social como ajuda, como já discutido, os usuários têm iniciativa própria e buscam a profissão com essa visão de auxílio. 
Quando indagados se já conheciam o serviço social em outra ocasião e reforçando os que procuraram ou foram encaminhados por profissionais internos, obteve-se o seguinte:

“Não! não! Só aqui mesmo. Foi aqui no Anita. [...] Eu procurei o serviço social por causa de uns exames" (Entrevistado 06); "Só lá do CRI11 somente. (Entrevistado 05).

Dessa forma, como profissão que circunda a sua imagem certa incompreensão de sua atuação, tanto pelos profissionais como pelos usuários, pensa-se: Como chega o usuário, que já foi admitido no serviço, a sala do serviço social dentro da instituição? A princípio a ida do usuário a sala do serviço social para ser atendido parte do profissional de referência dentro do CER que o atende, tal profissional mesmo sem saber ao certo o objeto de atuação da profissão julga que, na ausência de direitos ou na violação dele a atuação do serviço social é imprescindível.

Assim, relata usuária ao afirmar o pedido do profissional de referência para ir ao serviço social para "conversar": "Foi o fisioterapeuta que mandou eu procurar" (entrevistado 02). "[..] A primeira vez que eu fui pro serviço social do Anita, fui encaminhada pela neuropsicóloga, [...] (Entrevistado 04). Em outras ocasiões alguns usuários com mais formação em momentos específicos solicita a intervenção do serviço social:

\footnotetext{
“Não. Eu mesmo que procurei vim pra cá. Fiquei perguntando as pessoas que ganhavam fraldas, aí disseram que eu procurasse o serviço social e assistente social com assistente social se entende" (entrevistado 07).

"Procurei o serviço social por eu ter descobrido o caso do meu filho, aí fui procurar o serviço social para conseguir o benefício" (Entrevistado 08).
}

Assim, o serviço social está presente na realização das triagens e nas avaliações gerais da instituição, com um olhar mais crítico voltado para a esfera social. Pensando junto com a equipe que o usuário deve ser atendido de forma mais global e, é a partir de momentos específicos como esse relatado, como também nos grupos e rodas de conversas de diálogo em saúde, que as demandas vão surgindo e o serviço social identifica e faz a atuação necessária.

Há também, momento em que o serviço social identifica alguma demanda referente algum assunto do usuário e a procura para realizar a intervenção. Na fala da usuária retrata

\footnotetext{
${ }^{11}$ Centro de Reabilitação Infantil do Rio Grande do Norte.
} 
isso: "Ele (serviço social) me procurou pra vim falar comigo. Vocês daqui me procurou" (Entrevistado 05).

Nesses atendimentos, o serviço social faz as orientações na medida da compreensão do usuário, traz as informações necessárias para o entendimento de que ele é sujeito de direito. Para tanto, a profissão é inserida na luta histórica capital versus trabalho, e tendo como norte a defesa do direito da classe trabalhadora, atua no sentido de viabilização dos direitos daqueles que são negados e tem como atribuição contribuir para emancipação do cidadão a partir da transformação da realidade/vida desse usuário.

\section{O transporte como maior demanda}

A partir das entrevistas aplicadas aos usuários do CER foi percebido algumas demandas que chegam ao serviço social, entre tantas, as que segue no quadro abaixo são as mais comumente:

Quadro 2 - demandas dos entrevistados

\begin{tabular}{|l|l|l|l|}
\hline Entrevistados & Deficiência & Tempo de atendimento & Demandas/orientações \\
\hline 01 & Microcefalia & 4 anos e 3 meses & transporte \\
\hline 02 & Microcefalia & 6 meses & transporte \\
\hline 03 & parkinson & 1 anos e meio & transporte \\
\hline 04 & Lesão medular & 2 anos & transporte \\
\hline 05 & Lesão medular & 1 ano & transporte/educação \\
\hline 06 & parkinson & 1 ano e 8 meses & previdenciária/trabalhista \\
\hline 07 & Lesão medular & 7 anos & fraldas/transporte \\
\hline 08 & prematuro & 2 anos & BPC \\
\hline
\end{tabular}

Fonte: obtidos através das entrevistas, 2019.

Evidencia-se que a maior demanda é o meio de locomoção dos usuários de sua casa até o local do serviço, não foi percebida essa demanda apenas através das entrevistas mais também pelo cotidiano. Conforme o Estatuto ${ }^{12}$ da PcD, lei 13.146/15, o transporte gratuito é o meio de garantia de liberdade de ir e vir das PcD, e na indagação a um usuário a compreensão é como direito, como segue: "Eu vejo como direito. Eu creio que toda criança especial tem esse direito para ser "deportado" pra onde for" (Entrevistado 04). Mesmo assim, continua sendo um dos maiores entraves desse segmento na sociedade, pois quando se trata

\footnotetext{
12 Disponível em <http://www.planalto.gov.br/ccivil_03/_ato2015-2018/2015/lei/l13146.htm>
} 
de locomoção em cidades grandes que é o caso onde está localizado o CER Anita Garibaldi, a situação se torna mais complexa.

Mesmo que se tenha serviços de qualidade e acesso para todos, mas se não tem um sistema de transporte bem estruturado, o serviço ficará esvaziado por não ter como os usuários chegarem até ele. $\mathrm{O}$ transporte da $\mathrm{PcD}$ requer certos cuidados e excelência no meio que se utiliza para a locomoção dele, assim, o ônibus acessível com plataforma de elevação e a acessibilidade na arquitetura das vias públicas são imprescindíveis para a ida dele para a terapia.

Ressalta-se ainda que, a estrutura dos coletivos nas grandes cidades brasileiras, especificamente Natal e região metropolitana, falta muito para alcançar um patamar de excelência que transporte a PCD com qualidade. Entretanto, existe outras dificuldades nos meios de transportes, a gratuidade. Para se conseguir essa gratuidade para o livre acesso nos coletivos as PcD enfrentam uma verdadeira maratona nos órgãos que concede esse benefício.

Entre idas e vindas, a PcD precisa de documentações para comprovar a deficiência que em muitas vezes são aparentes. Laudos e declarações de atendimento contínuo no CER são os principais documentos que são solicitados, ainda outra solicitação constante é de comprovação de que precisa de acompanhamento para utilizar o transporte. Nesse momento o profissional de serviço social está junto ao usuário para acompanhar o processo e fazer as orientações.

Para além dessas questões, existem algumas localidades que não tem disponível o transporte coletivo e para esses usuários, conta-se com o transporte sanitário da secretaria de saúde dos municípios e para isso a intervenção do serviço social: [...] Aí, eu precisei procurar o serviço social do Anita pra entrar em contato com o secretário de saúde de lá onde moro pra poder conseguir um transporte" (entrevistado 04).

Nessa situação para garantir o acesso a esse benefício o serviço social precisa atuar com mais firmeza, pois nem sempre o órgão do município quer disponibilizar o transporte para esse translado mesmo sem oferecer o serviço de reabilitação em seu território. Observe o diálogo entre o usuário e o responsável pelo setor de transporte da secretaria de saúde de um município atendido pelo CER Anita Garibaldi: 
“- Senhor vim aqui pra colocar o nome dele (neto) pra levar ele pro Anita na sextafeira. Tá certo? (É difícil ele levar o carro. Já faz umas três semanas que a gente não sabe do carro. A gente vai lá e ele não manda). - Ah! Eu mandei, mas o motorista não acertou" (Entrevistado 05).

A alegação da usuária é que faz três semanas que não utiliza o transporte e que, possivelmente a criança fica sem atendimento devido à ausência do meio de locomoção. Ainda desabafa a usuária preocupada com um direito que é violado que resulta na fragmentação e descontinuação do atendimento: “É um direito que ele tem... é pra dar o carro pra qualquer canto que ele quiser. Uma consulta... carro tem que tá disponível pra trazer ele, né!? (Entrevistado 05)". Por isso, lamamoto (2009, p. 24) ressalta que: "assim as condições que circunscrevem o trabalho do assistente social expressam a dinâmica das relações sociais vigentes na sociedade."

Nesse processo o serviço social busca articular com o setor de transporte dos municípios, mostrando as dificuldades de saúde que o usuário passará se a descontinuidade do tratamento ocorrer. Ainda, ressalta que o transporte da PcD é um direito estabelecido em lei e que no não cumprimento deste a instância cabível será comunicada.

Cabe salientar que erroneamente os órgãos que emite a gratuidade de acesso aos transportes para as PcD na região metropolitana de Natal entende como saúde, única e exclusivamente, o atendimento nas unidades de saúde. A gratuidade é concedida apenas para o percurso: casa do usuário a unidade de saúde para o atendimento, desconsiderando os outros aspectos da vida do usuário que está atrelado ao ter saúde como o lazer.

Sobre o transporte sanitários da secretaria de saúde dos municípios que são atendidos no CER, percebeu-se que para eles PCD é apenas aquela que está acamada ou em cadeira de rodas. Portanto, o benefício do transporte é concedido para esses e para as demais deficiências existe resistência na concessão.

Diante disso, o serviço social junto com equipe do CER está planejando uma ação ou curso para contribuir com o processo de conscientização que a deficiência não se resume ao leito ou a cadeira de rodas.

\section{O serviço social na equipe multiprofissional}


Uma das discussões mais presentes nos espaços de saúde têm sido o trabalho em equipes multiprofissionais, na tentativa de alcançar a interprofissionalidade ${ }^{13}$ ou ainda transprofissionalidade ${ }^{14}$. A compreensão da atuação do serviço social nesse contexto não é algo de fácil apreensão, por um lado, há uma interação da profissão na equipe, melhorando sua articulação com os profissionais, por outro, pensa-se na descaracterização da profissão nestas equipes.

Antes de discutir o tema, se faz necessário saber que para o usuário a expressão equipe multiprofissional ou trabalho multidisciplinar causa um estranhamento e incompreensão para ele. Quando perguntado como percebia o trabalho do serviço social dentro da equipe multiprofissional e explicado o que era tal equipe, os usuários não compreendem dando outra resposta distante do perguntado, como segue: "A diferença é que o serviço social aqui dentro eles são acolhedores, entendeu? Eles "clarecem". Tem aquela boa vontade de conversar e tirar alguma dúvida (entrevistado 08).

Diante das entrevistas que foram surgindo que não correspondiam ao questionado e compreendendo que não foi entendida pelo usuário, a expressão equipe multiprofissional foi substituída por "equipe/trabalho em grupo" com outros profissionais. Mas, mesmo com a tentativa de deixar o diálogo mais compreensível a dificuldade de entender o que faz o serviço social e diferenciar dos demais profissionais perdurou. Portanto, o trabalho em equipe multiprofissional permanece como algo desconhecido no CER pelos usuários. Como segue:

\footnotetext{
"Pesquisador: - O serviço social faz parte de uma equipe de vários profissionais, psicólogo, médico, fono, fisioterapeuta. A senhora consegue ver o papel do serviço social dentro desta equipe? O que faz o serviço social? Entrevistado: - Quando a gente procura é bem atendido, trata as pessoas bem e atende nosso pedido [...]" (Entrevistado 07)
}

A equipe multiprofissional é formada com vista na centralidade da necessidade do usuário, ela não é pré-estabelecida e sim organizada e compostas pelas categorias profissionais conforme demanda apresentada. É através dos diversos olhares dos profissionais que a demanda do usuário é apreendida e trabalhada. Mesmo como verificado em estudos

\footnotetext{
${ }^{13}$ As profissões não estão apenas justapostas, mas com diálogo profundo e troca de conhecimentos contínuos em busca de uma solução para a situação posta.

${ }^{14}$ A partir dos pressupostos da interprofissionalidade surgem novas áreas de conhecimentos com a junção das profissões com autonomia teórica, técnica e disciplinar.
} 
científicos que o trabalho em equipe multiprofissional "costumam apresentar uma atitude pouco criativa e tarefeira" (MOZENA; OSTERMANN, 2017, p. 104).

Dessa forma, na tentativa de melhorar o trabalho em equipe multiprofissional, pensando no usuário como beneficiador dessa ação, a formação do profissional para adquirir conhecimento a respeito do tema e atuar em conformidade com o trabalho multiprofissional perpassa também pela percepção e compreensão do usuário sobre essa equipe e sua forma de intervenção. E, o serviço social inserido nesta equipe precisa esclarecer sua atuação composta pela articulação da rede e da viabilização de direitos, entre outras.

\section{Resolutividade da demanda e articulação do serviço social com a rede de serviços}

Outra categoria levantada na entrevista foi a resolutividade das demandas que chegam ao serviço social, no intuito de entender a resolução das necessidades dos usuários frente a categoria profissional no espaço. Nas falas foram encontradas respostas, ora positivas e ora negativas, como na que segue: "Foi a falta de transporte. Continua a mesma coisa, né! Ele (responsável do transporte) passou um tempo ... continua a mesma coisa" (entrevistado 05). "Teve "uns pegas aqui outro acolá", mas melhorou muito" (entrevistado 01).

Nem sempre cabe ao serviço social da unidade de saúde o resultado proveitoso e efetivo de uma demanda, o atendimento é feito no serviço, através de orientação e encaminhamento, mas a instituição/órgão que recebe a demanda em algumas ocasiões não dá seguimento propício para a solicitação, às vezes, talvez, por questões de ordem técnicas e/ou institucional. Considerando o exposto há algumas falas inseguras da resolução das demandas:

\footnotetext{
"Sobre o carro? Agora se Deus quiser tudo vai dar certo. "Tô" conversando com você (pesquisador), agora vai dar certo. Agora toda sexta vai tá aqui" (entrevistado 05). "Toda sexta-feira se o carro viesse, o transporte agora seria melhor, mas não tá vindo, aí não posso dizer que tá melhor" (Entrevistado 05).
}

Sendo assim, mesmo depois do usuário estar orientado e com o encaminhamento nas mãos, se faz necessário a intervenção junto ao responsável do órgão que receberá a demanda. É uma forma de reafirmar o que está documentado e se fazer ciente da demanda do usuário diante do órgão em que se pleiteia a resolutividade da necessidade. Nesse sentido, ainda fortalece o vínculo com usuário quando se mostra certa preocupação com a solicitação dele e se dar uma resposta a ele da intervenção realizada. 
Em relação as intervenções do serviço social do CER com as redes socioassistenciais, quando perguntado aos usuários das mudanças ocorridas após a atuação do profissional as respostas são variadas, mas com teor de melhoras.

\footnotetext{
“Assim, porque às vezes a gente vem fazer uma consulta. Ai, marca a consulta assim em cima da hora que a gente nem sabe. Porque lá (secretaria de saúde) tem que avisar 10 dias antes. Mas, quando a gente chega assim com uma consulta eles não dizem mais nada só fazem marcar" (Entrevistado 04).
}

A usuária explica que após a intervenção do serviço social junto ao órgão demandante as consultas mais urgências que são marcadas, e ela própria comunica ao setor de transporte da secretaria de saúde do município de origem é bem acolhida, enquanto que orientam que as consultas devem ser avisadas com no mínimo 10 dias de antecedência para que o transporte seja disponibilizado. Ainda conforme outra usuária a dispensa de fraldas foi efetivada após a atuação do serviço social como se ver na fala: "A gente não "tava" recebendo fralda lá. Depois que o serviço social ajudou eu passei a receber 100 por mês" (entrevistado 07).

Portanto, a atuação da categoria profissional no espaço, visando a garantia de direito do usuário, se efetiva nos retornos satisfatórios recebidos, mas nem sempre ocorre no primeiro contato ou tentativa realizada de resolução da demanda. Assim, em algumas ocasiões é necessário articulação, diálogo e insistência para alcançar o direito do usuário.

\section{Considerações finais}

O estabelecer da imagem da profissão pela visão dos usuários, como proposta deste estudo tem estrita ligação com a garantia de acesso a saúde em sentido geral e no CER. É através dessa percepção do usuário que o serviço social pode se auto avaliar como profissão que atual na viabilização dos direitos e articulador da rede de serviços dentro do espaço de saúde, no intuito de entender o seu alcance e suas fragilidades na inserção na sociedade.

Mas, a restrição da política social na sociabilidade capitalista pelos princípios neoliberais afeta diretamente esse mecanismo que beneficia os usuários do serviço, no sentido de não garantir acesso a todos, na seletividade da demanda, alcançando atendimento uma parcela ínfima dos que necessitam da intervenção em saúde. 
Nesse contexto de desconstrução da política de saúde, o serviço social é agente importante no espaço sociotécnico do trabalho para a enfraquecimento da lógica de retirada do ente público da cena social, mas, ainda é compreendido como uma ajuda oficializada no interior das instituições. Como já afirmado, a profissão tem ligação estreita em sua origem com o pensamento católico (neotomista), mas que no processo histórico foi desconstruído em vistas as mudanças sociais e não correspondência dessa abordagem as demandas que foram se complexificando.

Mesmo assim, com o rompimento do tradicionalismo na profissão ainda perdura nos espaços de trabalho essa visão ultrapassada da profissão que refletiram no resultado das entrevistas aplicadas neste estudo. Na contracorrente desta percepção está o serviço social do CER lutando constantemente na desarticulação dessa compreensão que paira na profissão no contexto brasileiro, bem como, no locus onde se desenvolveu a pesquisa.

Ainda nessa perspectiva há um constructo de que a profissão por ser permeada por um atuar conservador, onde a caridade, o apostolado, visa o ajustamento de comportamento dos usuários, transparece uma conduta passiva, tanto no contexto político mais amplo, como no espaço interno das unidades de trabalho onde a profissão desempenha seu ofício. Mas, não passa de um resquício de uma origem embebida no tradicionalismo.

Assim, no CER a profissão está presente nas equipes multiprofissionais nos momentos de intervenção e aí o serviço social faz uma busca de demandas dos usuários, que muitas vezes nem sabe que necessitam da intervenção do profissional. Em outras ocasiões os profissionais encaminham para a sala do serviço social para a devida intervenção e acompanhamento da demanda, e em outros ainda em conversa não oficial se identifica alguma demanda referente aquele usuário e a atuação é realizada.

São nesses momentos que as demandas vão surgindo e o serviço social vai apresentando sua imagem diante dos usuários e as necessidades, como a de transporte tão discutida aqui vai se manifestando. E na medida das possibilidades as respostas aos usuários vão sendo construídas através dos encaminhamentos, das articulações, dos contatos por email e telefones, das reuniões e dos planejamentos.

Dessa forma, conforme discurso dos usuários a profissão tem construído seu espaço e atendido as necessidades deles. Apesar das inúmeras dificuldades e desafios postos a 
profissão no espaço sociotécnico do trabalho, ela tem correspondido às solicitações através da busca incessante de meios e de caminhos para a resolução das demandas que surgem no escopo de atuação profissional.

É ainda a profissão, nas palavras dos usuários àquela que orienta, tira dúvidas, esclarecem o direito, "ajuda" a resolver os problemas, escuta com atenção, protege aqueles que não conhece seus direitos, é o apoio que se precisa para exigir que funcione determinado serviço. Diante de tanta adjetivação positiva e tratando-os com um pouco de teor acadêmico chega-se a uma profissão que inscrita numa sociedade de contradição tem um espaço determinado de atuação ao lado do usuário, mesmo sabendo que esse é o lado mais frágil se afirmar na luta política pela emancipação do ser humano.

Para tanto, a qualificação e universalização da política de saúde como política social inscrita na sociedade precisa ser abrangente para acolher a todos que dela precisar, pois as contribuições para a sustentação do Sistema Único de Saúde parte das contribuições dos cidadãos.

Nesse sentido, a luta para tornar o CER acessível a todos de forma igualitária e equânime é tarefa constante do serviço social e de todas as categorias profissionais, bem como, da comunidade atendida na unidade de saúde.

\section{Referências}

ALMEIDA, N. L. T. de; ALENCAR, M.M. T.. Serviço social, trabalho e políticas públicas. São Paulo: Saraiva, 2011.

APARECIDA DE SOUZA, L. MANCUSSI E FARO, A. C. História da reabilitação no Brasil, no mundo e o papel da enfermagem neste contexto: reflexões e tendências com base na revisão de literatura. Revista Eletrônica Trimestral de Enfermagem: Enfermagem Global, no 24, São Paulo. Disponível em <https://bdpi.usp.br/item/002276786>. Acessado em 26 de fev. de 2019.

BARISON, M. S.; GONÇALVES, R. S.; Judicialização da questão social e a banalização da interdição de pessoas com transtornos mentais. Serv. Soc. Soc., São Paulo, n. 125, p. 41-63, jan./abr. 2016. Disponível em <http://www.scielo.br/pdf/sssoc/n125/0101-6628-sssoc-1250041.pdf>.

BARTALOTTI, C. C. Inclusão social das pessoas com deficiência: utopia ou possibilidade? - São Paulo: Paulus, 2010. 
BRASIL. Presidência da República Casa Civil. Subchefia para Assuntos Jurídicos. LEI № 9.637, $D E 15$ DE MAIO DE 1998. Dispõe sobre a qualificação de entidades como organizações sociais, a criação do Programa Nacional de Publicização, a extinção dos órgãos e entidades que menciona e a absorção de suas atividades por organizações sociais, e dá outras providências. Disponível em http://www.planalto.gov.br/ccivil_03/leis/19637.htm

BRASIL. Ministério da saúde. Manual de Ambiência dos Centros Especializados em Reabilitação (CER) e das Oficinas Ortopédicas Orientações para Elaboração de Projetos (Construção, Reforma e Ampliação), 2013. Disponível em <http://www.saude.am.gov.br/planeja/doc/rts/apresentacao_24_08_2018/orientacoes_ela boracao_proposta_pessoadeficiente.pdf>. Acessado em 27 de dez. de 2018.

Ministério da saúde. PORTARIA № 793, DE 24 DE ABRIL DE 2012. Institui a Rede de Cuidados à Pessoa com Deficiência no âmbito do Sistema Único de Saúde. Disponível em <http://bvsms.saude.gov.br/bvs/saudelegis/gm/2012/prt0793_24_04_2012.html>. Acessado em 29 de dez. de 2018.

Convenção sobre os Direitos das Pessoas com Deficiência: Protocolo Facultativo à Convenção sobre os Direitos das Pessoas com Deficiência: Decreto Legislativo no 186, de 09 de julho de 2008. Decreto n 6.949, de 25 de agosto de 2009. 3 Ed., rev. e atual._Brasília: Secretaria de Direitos Humanos.

Secretaria Nacional de Promoção dos Direitos da Pessoa com Deficiência, 2010. Disponível em <http://www.planalto.gov.br/ccivil_03/_ato20072010/2009/decreto/d6949.htm> Acessado em 05 de mar. de 2019.

IBGE. Projeção da população do Brasil e das unidades federadas. 2010. Disponível em <https://www.ibge.gov.br/apps/populacao/projecao/>. Acessado em 10 de dez. de 2019.

Decreto-lei no 6.949, de 25 de agosto de 2009. Convenção Internacional sobre os direitos das pessoas com deficiência. Disponível em <http://www.planalto.gov.br/ccivil_03/_ato2007-2010/2009/decreto/d6949.htm>. Acessado em 05 de mar. de 2019.

BRASIL. Código de ética do/a assistente social. Lei 8.662/93 de regulamentação da profissão. 10 ed. rev. e atual. - Brasília: Conselho Federal de Serviço Social, 2012.

GUERRA, Y. A instrumentalidade do Serviço Social. São Paulo: Cortez, 2007.

, Y. Instrumentalidade do processo de trabalho e Serviço Social. In: Revista Serviço Social e Sociedade n. 62. São Paulo: Cortez, 2000.

IAMAMOTO, M. V.. O serviço social na contemporaneidade: trabalho e formação profissional. 15 Ed. São Paulo, 2008.

O serviço social na cena contemporânea. In: serviço social: direitos sociais e competências profissionais. Brasília: CFESS/ABEPSS, 2009, p. 15-50. 
YAZBEK, M. C. O significado sócio-histórico da profissão. In Serviço Social: Direitos Sociais e competências profissionais. Brasília: CFESS /ABEPSS. 2009.

MOZENA, E. R.; OSTERMANN, F. Dialogando sobre a interdisciplinaridade em Ivani Catarina Arantes Fazenda e alguns dos integrantes do grupo de estudos e pesquisa em interdisciplinaridade da PUC-SP (GEPI). Revista interdisciplinaridade, São Paulo, n. 10, p. 95107, 2017. Disponível em <https://revistas.pucsp.br/interdisciplinaridade/article/view/32444>. Acessado em 26 de dez. de 2019.

NETTO, J.P. A construção do projeto ético-político do Serviço Social. Disponível em: http://www.abepss.org.br/arquivos/anexos/a-construcao-do-projeto-eticopolitico-doservico-social-201608060411147630190.pdf Acesso em: 07 de agost. 2020.

ORGANIZAÇÃO DAS NAÇÕES UNIDAS PARA A EDUCAÇÃO, A CIÊNCIA E A CULTURA, UNESCO. MARIA REBECA OTERO GOMES, Coordenadora Setor de Educação. Pessoas com deficiência no Brasil. Disponível em $<$ http://www.unesco.org/new/pt/brasilia/education/inclusive-education/persons-withdisabilities/>. Acessado em 21 de dez. de 2018.

PITA, M. Deficientes representam 24\% da população do Brasil, diz IBGE. 2011. Disponível em <https://www.terra.com.br/economia/terra-da-diversidade/deficientes-representam-24-dapopulacao-do-brasil-diz-ibge,7258b920548da310VgnCLD200000bbcceb0aRCRD.html>. Acessado em 10 de dez. de 2019.

PEREIRA, J. de S. MACHADO, W. C. A. Implantação de centro especializado em reabilitação: vantagens e desvantagens apontadas pelos gestores municipais de saúde. Rev Ter Ocup Univ São Paulo. 2015 set.-dez.;26(3):373-81. Disponível em <http://dx.doi.org/10.11606/issn.2238-6149.v26i3p373-381>. Acessado em 26 de fev. de 2019.

SOUZA, D. de O.; SILVA, S. E. V. da; SILVA, N. de O. Determinantes Sociais da Saúde: reflexões a partir das raízes da "questão social". Saúde e Sociedade. São Paulo, v. 22, n.i, p. 44-56, 2013.

XAVIER, M. de A. A. Assistência Social e pessoa com deficiência: um estudo sobre os programas e serviços ofertados à pessoa com deficiência nos Centros de Referência de Assistência Social/CRAS na zona leste e norte da cidade de Manaus. Manaus, 2015. Disponível em <https://tede.ufam.edu.br/bitstream/tede/5309/2/Disserta\%C3\%A7\%C3\%A30\%20\%20M\%C3\%A1rcia\%20A.\%20A.\%20Xavier.pdf>. Acessado em 10 de dezembro de 2019.

Recebido em: 29.03.2020 Aceito em: 24.10.2020 